Analisis Kestabilan dan Usaha Pemanenan Model Predator Prey Tipe Holling III dengan Keuntungan Maksimum

\title{
Stability Analysis and Harvesting Effort Predator Prey Populations Model Holling Type III with Maximum Profit
}

\author{
Didiharyono $^{1}$ and Muh. Irwan ${ }^{2}$ \\ ${ }^{1}$ Universitas Andi Djemma Palopo, Email: muh.didih@gmail.com \\ ${ }^{2}$ UIN Alauddin Makassar, Email: muhirwan@uin-alauddin.ac.id
}

\begin{abstract}
In this paper discussed stability analysis and harvesting effort at second predator prey populations model Holling type III with maximum profit. The step this research is to determine the equilibrium point, linearize the model, stability analysis of the equilibrium point, and numerical simulation. Result shows that obtained an interior point $T E_{2}^{*}\left(N_{1}^{*}, N_{2}^{*}\right)$ that asymptotic stable based on Hurwitz stability test then obtained maximum profit from exploitation harvesting effort of second predator prey populations. This second populations will always exist, even though exploited with harvesting effort done by humans. Harvesting effort of second predator-prey populations given maximum profit $\left(\pi_{\max }\right)$ that occur on critical points of surface profit function.
\end{abstract}

Keyword: Equilibrium point, stability, harvesting effort and maximum profit.

\begin{abstract}
Abstrak
Paper ini menjelaskan tentang analisis kestabilan dan usaha pemanenan pada kedua model predator prey tipe Holling III dengan keuntungan maksimum. Langkah-langkah penelitian yang dilakukan meliputi penentuan titik keseimbangan, melinearkan model, analisis kestabilan dari titik keseimbangan dan simulasi numerik. Hasil penelitian menunjukan bahwa model mangsa pemangsa tipe Holling III dengan usaha pemanenan pada kedua populasi tersebut. Sehingga, dapat ditunjukan bahwa titik interior $T_{2}^{*}\left(N_{1}^{*}, N_{2}^{*}\right)$ stabil asimptotik berdasarkan kestabilan Hurwitz test dan diperoleh nilai keuntungan maksimal berdasarkan kegiatan usaha pemanenan pada populasi mangsa pemangsa tersebut. Populasi mangsa pemangsa akan tetap eksis (bertahan hidup) meskipun dilakukan usaha pemanenan dan dapat memberikan nilai keuntungan maksimal $\left(\pi_{\max }\right)$ dari usaha pemanenan yang dimungkinkan terjadi pada puncak (titik kritis) suatu permukaan fungsi keuntungan.
\end{abstract}

Kata Kunci: Titik Keseimbangan, Kestabilan, Usaha Pemanenan dan Keuntungan Maksimum 


\section{PENDAHULUAN}

Keberadaan pemodelan matematika terus mendukung perkembangan ilmu terapan lainnya. Penerapan pemodelan matematika tidak hanya ditemukan matematika dan statistika saja, namun pemodelan matematika hampir dapat dijumpai pada seluruh cabang ilmu pengetahuan baik kedokteran, biologi, ekologi, ekonomi dan ilmu pengetahuan terapan lainnya. Menurut (Toaha, 2013) model matematika ini berkontribusi dalam memudahkan fenomena alam yang abstrak untuk disimulasikan dalam bentuk rumusan matematika. Kemudian model matematika digeneralisasikan dan diformalisasikan dengan metode khusus sebagaimana yang ada dalam metodologi penelitian matematika terapan.

Model matematika juga digunakan dalam menjelaskan suatu fenomena faktual yang terjadi dan juga digunakan dalam memperkirakan perilaku sistem dalam perkiraan waktu tertentu. Penerapan pemodelan matematika dibidang kesehatahan, biologi, ekologi dan ekonomi menarik untuk teliti lebih mendalam mengingat beberapa faktor-faktor yang dapat mempengaruhi kehidupan organisme (mahluk hidup), ekosistem (lingkungan) dan keseimbangan (equiblirium) kehidupan mahluk hidup serta interaksi mereka dalam keberlanjutan kehidupan manusia. Proses dinamika kehidupan organisme yang terjadi dapat dimodelkan dalam bentuk matematis suatu persamaan differensial dengan waktu kontinu dan waktu yang diskrit (Agarwal, 2012). Pemodelan matematika juga dimaknai sebagai usaha merumuskan dengan metode matematika dalam menggambarkan penyelesaian masalah yang digeneralisasikan pada suatu perilaku sistem dan fenomena alam yang terjadi.

Model matematika yang tepat digunakan dalam menyelesaikan fenomena yang terjadi secara faktual tersebut yaitu model predator prey (mangsa pemangsa). Hubungan yang terjadi antara populasi pemangsa dan populasi mangsa sangat berkaitan antara keduanya, pemangsa tidak akan dapat bertahan dalam kehidupannya jika tidak ditemukan populasi yang dimangsa. Selain itu, pemangsa memiliki peran dalam mengontrol perkembangan spesies populasi mangsa. Menurut (Toaha, 2013) bahwa interaksi antar populasi mangsa pemangsa yang terjadi dalam suatu lingkungan populasi dapat menyebabkan kondisi populasi organisme bisa berubah jika terjadi interaksi antara mangsa pemangsa. Proses kegiatan interaksi tersebut berdampak positif, berdampak negatif atau bahkan tidak memiliki pengaruh terhadap interaksi populasi organisme. Salah satu penyebab yang dominan dari punahnya spesies populasi mangsa yaitu terjadi tingkat pemangsaan yang sangat tinggi terhadap populasi mangsa, sementara tingkat kelahiran (pertumbuhan) mangsa sangat rendah atau bisa juga 
disebabkan karena populasi awal yang kecil (sedikit) dibandingkan dengan pertumbuhan mangsa.

Beberapa peneliti yang mengkaji model mangsa pemangsa atau dikenal juga dengan model Lotka Volterra dengan penambahan asumsi-asumsi yang berbeda-beda. Diantaranya (Dubey dkk, 2018) meneliti model Lotka Voltera dengan tipe Crowley Martin fungsi respon dan tahapan struktur pada predator. Kemudian, (Kar, 2005) mengkaji model Lotka-Voltera dengan model menggabungkan perlindungan mangsa. Selanjutnya, (Toaha, dkk, 2008; Zhang, Xu, \& Gan, 2011) membahas model mangsa pemangsa tersebut dengan penambahan fungsi respon tipe Holling III pada kegiatan interaksi antara populasi mangsa pemangsa dengan penambahan asumsi usaha pemanenan konstan hanya pada populasi mangsa (prey). Kemudian, (Dubey dkk, 2018; Jiang \& Wang, 2013) membahas model yang sama dengan menambahkan asumsi usaha pemanenan konstan pada kedua populasi tersebut. Model yang sama juga dikembangan dalam (Liu \& Xing, 2012; Didiharyono, 2016) yang fokus mengkaji usaha pemanenan populasi dua pemangsa dengan satu mangsa dan menambahkan asumsi pada populasi mangsa dengan penyertaan mangsa pelarian (refuge). Dan pada penelitian (Zhao, Zhao, \& Yu, 2013) mencoba melihat efek kehadiran populasi mangsa pelarian (refuge) tersebut yang mempengaruhi kondisi awal populasi mangsa.

Berdasarkan penjelasan di atas, maka penulis membahas analisis kestabilan model mangsa pemangsa tipe Holling III pada populasi mangsa-pemangsa (predator-prey) dengan penambahan asumsi usaha pemanenan pada kedua populasi tersebut merupakan suatu spesies yang sangat bermanfaat untuk kehidupan manusia. Kegiatan usaha pemanenan yang terjadi dapat bernilai ekonomis dan menguntungkan bagi kehidupan manusia tanpa merusak ekosistem organisme. Tujuan dari penelitian yaitu untuk memperoleh solusi model mangsapemangsa tipe Holling III dengan penyertaaan usaha pemanenan pada populasi mangsapemangsa dan juga mengetahui besar keuntungan maksimum dari kegiatan usaha pemanenan optimal pada kedua populasi tersebut.

\section{METODE PENELITIAN}

Adapun jenis penelitian ini yaitu penelitian kuantitatif dengan bantuan data simulasi. Kegiatan penelitian dimulai dengan konstruksi model mangsa-pemangsa, penentuan titik keseimbangan, melinearisasi suatu model, menganalisis kestabilan dari titik keseimbangan, selanjutnya melakukan simulasi numerik (Didiharyono, 2016; S. Toaha, 2013) dengan 
menggunakan software komputer. Variabel penelitian yang digunakan yaitu variabel model populasi mangsa pemangsa tipe Holling III dengan usaha pemanenan yang terjadi pada kedua populasi mangsa pemangsa. Dalam proses simulasinya menggunakan bantuan software komputasi yaitu Maple dalam proses penentuan titik kestabilan, keuntungan maksimum dan pembuatan gambar.

\section{HASIL DAN PEMBAHASAN}

Hasil penelitian ini ditunjukkan bahwa model populasi mangsa pemangsa tipe Holling III diperoleh dua titik keseimbangan. Salah satu titik keseimbangan tersebut merupakan suatu titik interior yang dalam kondisi stabil asimptotik menurut kestabilan Hurwitz test. Kemudian, terjadi usaha pemanenan pada kedua populasi mangsa pemangsa yang dapat memberikan keuntungan maksimal bagi kehidupan manusia. Berikut ini ditunjukan model populasi mangsa pemangsa tipe Holling III pada Persamaan (1.1)

$$
\begin{aligned}
& \frac{d N_{1}}{d t}=r N_{1}\left(1-\frac{r N_{1}^{2}}{K}\right)-\frac{m_{1} N_{2} N_{1}^{2}}{a_{1}+N_{1}^{2}} \\
& \frac{d N_{2}}{d t}=\frac{m_{1} N_{2} N_{1}^{2}}{a_{1}+N_{1}^{2}}-\beta N_{2}
\end{aligned}
$$

Suatu asumsi dari kedua populasi mangsa pemangsa tersebut yaitu bahwa populasi yang sangat bermanfaat dan memberikan nilai ekonomis untuk kehidupan manusia. Sehingga, pada kedua populasi tersebut dapat dilakukan eksploitasi dengan usaha pemanenan masing-masing kedua populasi mangsa pemangsa. Selanjutnya, dengan memperhatikan model Persamaan (1.1) maka dikembangkan menjadi,

$$
\begin{aligned}
\frac{d N_{1}}{d t} & =r N_{1}\left(1-\frac{r N_{1}^{2}}{K}\right)-\frac{m_{1} N_{2} N_{1}^{2}}{a_{1}+N_{1}^{2}}-q_{1} E_{1} N_{1} \\
\frac{d N_{2}}{d t} & =\frac{m_{1} N_{2} N_{1}^{2}}{a_{1}+N_{1}^{2}}-\beta N_{2}-q_{2} E_{2} N_{2}
\end{aligned}
$$

Dimana,

\begin{tabular}{lll}
\hline No & Simbol & Keterangan \\
\hline $\mathbf{1}$ & $N_{1}, N_{2}$ & Ukuran populasi predator-prey \\
\hline $\mathbf{2}$ & $r$ & Laju pertumbuhan intrinsik \\
\hline $\mathbf{3}$ & $K$ & Daya dukung lingkungan (Carrying capacity) \\
\hline $\mathbf{4}$ & $E_{1, E_{2}}$ & Usaha pemanenan pada populasi predator-prey \\
\hline $\mathbf{5}$ & $m_{1}$ & Laju kelahiran predator \\
\hline
\end{tabular}




\begin{tabular}{lll}
\hline $\mathbf{6}$ & $a_{1}$ & Konstanta kejenuhan predator \\
\hline $\mathbf{7}$ & $\beta$ & Laju kematian predator \\
$\mathbf{8}$ & $q_{1}$ dan $q_{2}$ & Koefisien ketertangkapan
\end{tabular}

Dengan memisalkan $r_{1}=r-q_{1} E_{1}$ dan $r_{2}=\beta+q_{2} E_{2}$, maka model (1.2) menjadi

$$
\begin{aligned}
& \frac{d N_{1}}{d t}=r_{1} N_{1}-\frac{r N_{1}^{2}}{K}-\frac{m_{1} N_{2} N_{1}^{2}}{a_{1}+N_{1}^{2}} \\
& \frac{d N_{2}}{d t}=\frac{m_{1} N_{2} N_{1}^{2}}{a_{1}+N_{1}^{2}}-r_{2} N_{2}
\end{aligned}
$$

Berdasarkan model (1.3) diperoleh dua titik ekuilibrium yang non negatif, yaitu $T E_{l}\left(N_{1}, N_{2}\right)=(0,0)$ dan $T E_{2}\left(N_{1}, N_{2}\right)=\left(\alpha, \frac{a_{1}\left(r_{1} K-r\right)}{\left(m_{1}-r_{2}\right) \alpha K}\right)$ dimana, $\alpha$ merupakan akar-akar dari persamaan $\left(m_{1}-r_{2}\right) Z^{2}-r_{2} a_{1}$. Titik $T E_{2}(x, y)$ adalah suatu titik yang diperkirakan terjadi pada oktan pertama titik interior, dengan $\alpha>0, a_{1}+\alpha^{2}>0$ dan $a_{2}+\alpha^{2}>0$ yaitu suatu kondisi dimana kedua titik keseimbangan tersebut semuanya bernilai positif. Sehingga, analisis kestabilan cukup dilakukan pada salah satu titik keseimbangan yaitu titik keseimbangan $T E_{2}\left(N_{1}, N_{2}\right)$ yang non negatif.

Titik keseimbangan $T E_{2}\left(N_{1}, N_{2}\right)$ model persamaan (1.1) diperoleh dengan menyelesaikan $\frac{d N_{1}}{d t}=0$, dan $\frac{d N_{2}}{d t}=0$, kemudian melinearisasi model (1.3) dalam bentuk matriks Jacobian berikut.

$$
A=\left(\begin{array}{ll}
\frac{\partial f_{1}}{\partial N_{1}} & \frac{\partial f_{1}}{\partial N_{2}} \\
\frac{\partial f_{2}}{\partial N_{1}} & \frac{\partial f_{2}}{\partial N_{2}}
\end{array}\right)
$$

Untuk menentukan nilai eigen matriks A dengan ordo $3 \quad x \quad 3$ digunakan persamaan $\operatorname{det}(\mathbf{A}-\lambda \mathbf{I})=0$, sampai memperoleh persamaan karateristik matriks $\mathbf{A}$ yang berbentuk $f(\lambda)=\lambda^{2}+a_{1} \lambda+a_{0}$ atau $f(\lambda)=\lambda^{2}+\left(\frac{r_{1} K-r}{K}-r_{2}\right) \lambda+\left(\frac{r_{1} r_{2} K-r}{K}\right)$. Menurut kriteria kestabilan Routh-Hurwitz dalam (Toaha, 2013; Kar, 2005) titik $T E_{2}\left(N_{1}, N_{2}\right)$ yang stabil asimptotik jika dan hanya jika $a_{1}, a_{0}>0$. Pada teknik melinearisasi model dan uji kestabilan Hurwitz, diperoleh titik $T E_{2}\left(N_{1}, N_{2}\right)$ yang stabil asimptotik sebagaimana kondisinya ditunjukan pada Gambar (1) dan Gambar (2) berikut. 


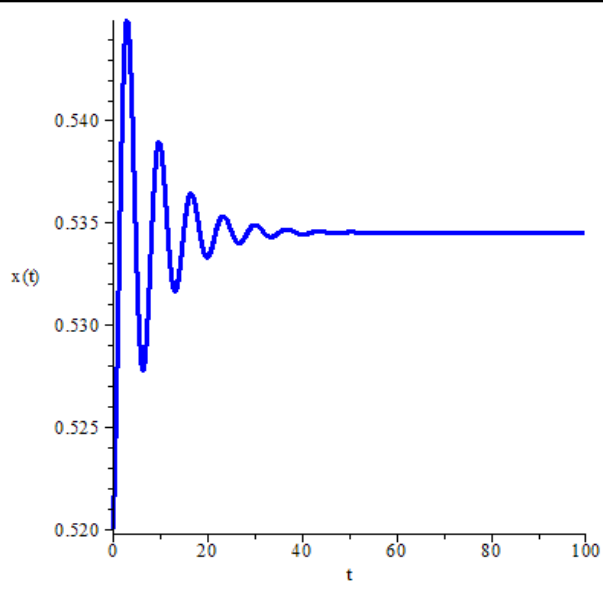

Gambar (1) Bentuk kurva kestabilan mangsa

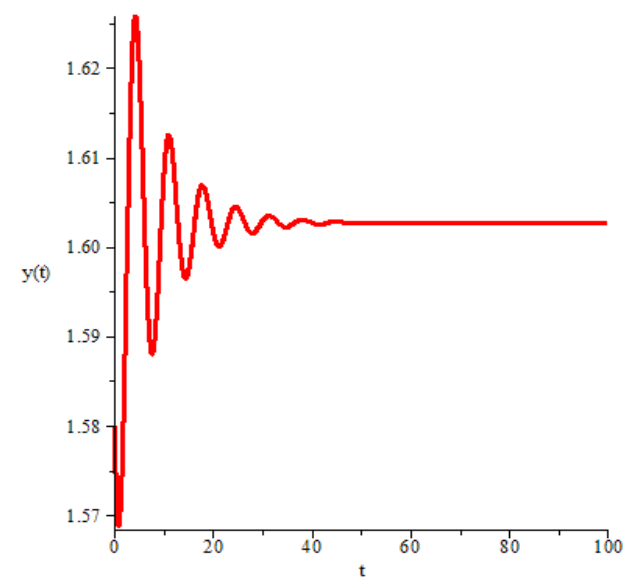

Gambar (2) Bentuk kurva kestabilan pemangsa

Karena pada posisi titik keseimbangan $T E_{2}\left(N_{1}, N_{2}\right)$ pada persamaan (1.2) menunjukan terjadinya kegiatan usaha pemanenan pada populasi mangsa pemangsa dengan asumsi bahwa $r-q_{1} E_{1}>0$ dan $\beta+q_{2} E_{2}>0$, serta dengan memisalkan $r_{1}=r-q_{1} E_{1}$ dan $r_{2}=\beta+$ $q_{2} E_{2}$ maka $T E_{2}\left(N_{1}, N_{2}\right)$ menjadi $T E_{2}^{*}\left(N_{1}^{*}, N_{2}^{*}\right)=\left(\alpha\left(r-q_{1} E_{1}\right), \frac{a_{1}\left(r_{1} K-r\right)\left(\beta+q_{2} E_{2}\right)}{\left(m_{1}-r_{2}\right) \alpha K}\right)$.

Selanjutnya, titik keseimbangan $T E_{2}^{*}\left(N_{1}^{*}, N_{2}^{*}\right)$ yang dalam keadaan stabil asimptotik tersebut, dilakukan perhitungan penerimaan total (TR), menentukan biaya total (TC) dan menentukan keuntungan maksimal $(\pi)$ karena terjadinya kegiatan usaha pemanenan. Kemudian, memisalkan unit harga untuk stok populasi $N_{1}$ dan populasi $N_{2}$ dinyatakan sebagai $p_{1}$ dan $p_{2}$. Biaya total diasumsikan dengan proporsional hasil tangkapan dengan usaha pemanenan dengan simbol $E_{1}$ dan $E_{2}$ dan bentuk koefisien $c_{1}$ dan $c_{2}$. Dalam (Toaha, 2013) fungsi penerimaan total (TR) sebagaimana ditunjukan dalam Persamaan (1.4) berikut ini,

$$
\begin{aligned}
\operatorname{TR}\left(N_{i}\right) & =T R\left(N_{1}\right)+\operatorname{TR}\left(N_{2}\right) \\
& =p_{1} E_{1} N_{1}^{*}+p_{2} E_{2} N_{2}^{*}
\end{aligned}
$$

Langkah selanjutnya, mensubstitusikan nilai $N_{1}^{*}$ dan $N_{2}^{*}$ pada dalam persamaan (1.4) sehingga diperoleh,

$$
\begin{aligned}
T R & =p_{1} E_{1}\left(\alpha\left(r-q_{1} E_{1}\right)\right)+p_{2} E_{2}\left(\frac{a_{1}\left(r_{1} K-r\right)\left(\beta+q_{2} E_{2}\right)}{\left(m_{1}-r_{2}\right) \alpha K}\right) \\
& =p_{1} E_{1}\left(\alpha r-\alpha q_{1} E_{1}\right)+p_{2} E_{2}\left(\frac{a_{1} r_{1} \beta K+a_{1} r_{1} K q_{2} E_{2}-a_{1} \beta r-a_{1} r q_{2} E_{2}}{\left(m_{1}-r_{2}\right) \alpha K}\right)
\end{aligned}
$$




$$
\begin{aligned}
& =p_{1} E_{1}\left(\alpha r-\alpha q_{1} E_{1}\right)+p_{2} E_{2}\left(\frac{a_{1} r_{1} \beta K+a_{1} r_{1} K q_{2} E_{2}-a_{1} \beta r-a_{1} r q_{2} E_{2}}{\left(m_{1}-r_{2}\right) \alpha K}\right) \\
& =p_{1} E_{1} \alpha r-p_{1} \alpha q_{1} E_{1}^{2}+\frac{p_{2} a_{1} r_{1} \beta K E_{2}+p_{2} a_{1} r_{1} K q_{2} E_{2}^{2}-p_{2} a_{1} \beta r E_{2}-p_{2} a_{1} r q_{2} E_{2}^{2}}{\left(m_{1}-r_{2}\right) \alpha K} 111 \\
& =p_{1} E_{1} \alpha r-p_{1} \alpha q_{1} E_{1}^{2}+\frac{p_{2} a_{1} r_{1} \beta K E_{2}-p_{2} a_{1} \beta r E_{2}+p_{2} a_{1} r_{1} K q_{2} E_{2}^{2}-p_{2} a_{1} r q_{2} E_{2}^{2}}{\left(m_{1}-r_{2}\right) \alpha K} \\
T R & =p_{1} E_{1} \alpha r-p_{1} \alpha q_{1} E_{1}^{2}+\frac{p_{2} \beta a_{1}\left(r_{1} K-r\right) E_{2}}{\left(m_{1}-r_{2}\right) \alpha K}+\frac{p_{2} q_{2} a_{1}\left(r_{1} K-r\right) E_{2}^{2}}{\left(m_{1}-r_{2}\right) \alpha K}
\end{aligned}
$$

Menurut (eToaha, 2013) fungsi biaya total (TC) dinyatakan sebagai berikut

$$
\mathrm{TC}=c_{1} E_{1}+c_{2} E_{2}
$$

Dengan melakukan substitusi nilai $T R$ sebagaimana pada bentuk Persamaan (1.5) dan substitusi nilai TC sebagaimana pada bentuk Persamaan (1.6) ke dalam $(\pi)$ maka diperoleh,

$$
\begin{aligned}
\pi & =\left(p_{1} E_{1} \alpha r-p_{1} \alpha q_{1} E_{1}^{2}+\frac{p_{2} \beta a_{1}\left(r_{1} K-r\right) E_{2}}{\left(m_{1}-r_{2}\right) \alpha K}+\frac{p_{2} q_{2} a_{1}\left(r_{1} K-r\right) E_{2}^{2}}{\left(m_{1}-r_{2}\right) \alpha K}\right)-\left(c_{1} E_{1}+c_{2} E_{2}\right) \\
& =\left(p_{1} \alpha r_{1}-c_{1}\right) E_{1}-p_{1} q_{1} \alpha E_{1}^{2}+\frac{p_{2} \beta a_{1}\left(r_{1} K-r\right)-\alpha K c_{2}\left(m_{1}-r_{2}\right)}{\left(m_{1}-r_{2}\right) \alpha K} E_{2}+\frac{p_{2} q_{2} a_{1}\left(r_{1} K-r\right)}{\left(m_{1}-r_{2}\right) \alpha K} E_{2}^{2}
\end{aligned}
$$

Karena titik keseimbangan $T E_{2}^{*}\left(N_{1}^{*}, N_{2}^{*}\right)$ bergantung pada usaha pemanenan yang dilakukan maka fungsi keuntungan juga bergantung dan didasarkan pada kegiatan usaha pemanenan. Selanjutnya, untuk menentukan keuntungan maksimal yang juga bergantung pada usaha pemanenan, maka perlu diketahui nilai titik kritis (titik puncak) dari kegiatan kegiatan pemanenan. Berdasarkan pada model Persamaan (1.7), di atas dapat ditentukan turunan pertama berikut,

$$
\begin{aligned}
& \frac{\partial \pi}{\partial E_{1}}=\left(p_{1} \alpha r_{1}-c_{1}\right) E_{1}-p_{1} q_{1} \alpha E_{1}^{2} \\
& \frac{\partial \pi}{\partial E_{2}}=\frac{p_{2} \beta a_{1}\left(r_{1} K-r\right)-\alpha K c_{2}\left(m_{1}-r_{2}\right)}{\left(m_{1}-r_{2}\right) \alpha K} E_{2}+\frac{p_{2} q_{2} a_{1}\left(r_{1} K-r\right)}{\left(m_{1}-r_{2}\right) \alpha K} E_{2}^{2}
\end{aligned}
$$

Nilai titik kritis dari model Persamaan (1.7) akan diperoleh dengan memisalkan model Persamaan (1.8) dengan nilai sama dengan nol. Sehingga, diperoleh titik kritis

a. Jika $\frac{\partial \pi}{\partial E_{1}}=0$, diperoleh $E_{1}=\frac{r_{1}-c_{1}}{2 q_{1}}$

b. Jika $\frac{\partial \pi}{\partial E_{2}}=0$, diperoleh $E_{2}=\frac{p_{2} a_{1} \beta\left(r_{1} K-r\right)-\alpha K c_{2}\left(m_{1}-r_{2}\right)}{2 p_{2} q_{2} a_{1}\left(r_{1} K-r\right)}$ 
Nilai-nilai usaha pemanenan $E_{1}$ dan $E_{2}$ memberikan titik keseimbangan $T E_{2}^{*}\left(N_{1}^{*}, N_{2}^{*}\right)$ berada dalam kondisi stabil asimptotik dan dapat memberikan keuntungan maksimal berdasarkan hasil eksploitasi dari usaha pemanenan pada kedua populasi mangsa pemangsa. Adapaun fungsi keuntungan pada kedua populasi mangsa pemangsa sangat bergantung pada nilai $E_{1}$ dan $E_{2}$ dengan keuntungan maksimal selalu terjadi dipuncak permukaan dari suatu fungsi keuntungan.

\section{SIMULASI NUMERIK}

Simulasi numerik dilakukan dengan memisalkan $K=1000, r_{1}=1,5, r=0.8, r_{2}=0.5, a_{1}$ $=0,4, m_{1}=1,2, p_{1}=0,1, p_{2}=0,3, c_{1}=0,1, c_{2}=0.2, q_{1}=0,4, q_{2}=0.4, \alpha=1,2, b=0,5$ serta pemanenan optimal $E_{1}=1.667, E_{2}=1.084$, sehingga diperoleh titik keseimbangan $\left(N_{1}=\right.$ 1,184104369; $\left.N_{2}=0.1678999787\right)$ dan juga memberikan $\pi_{\max }=162.679$. Semakin banyak usaha pemanenan yang dilakukan maka semakin banyak keuntungan yang didapatkan. Namun, jika menginginkan populasi mangsa pemangsa tetap lestari dan terjaga (tidak punah), maka usaha pemanenan dilakukan berdasarkan prosedur dan aturan yang berlaku, yaitu dengan mempertimbangkan kelahiran populasi mangsa pemangsa dan waku pelaksanaan pemanenan misalkan dilakukan setiap sekali seminggu.

Dengan melakukan linearisasi linearisasi model, diperoleh persamaan karakteristik $f(\lambda)=\lambda^{2}+0.07266918928 \lambda+0.05486989492$. Dari persamaan karakteristik diperoleh $p_{0}=0.05486989492$ dan $p_{l}=0.07266918928$. Karena $p_{0}, p_{1}>0$ maka berdasarkan kriteria uji kestabilan Hurwitz maka titik $T E_{2}^{*}\left(N_{1}^{*}, N_{2}^{*}\right)$ stabil asimptotik. Pada Gambar (3) dan Gambar (4) berikut, meunjukan bahwa kestabilan perilaku kurva solusi kedua populasi mangsa pemangsa terhadap waktu (dalam tahun), berada disekitar titik keseimbangan untuk nilai awal $N_{1}(0)=1.189$ dan $N_{2}(0)=0.168$. 


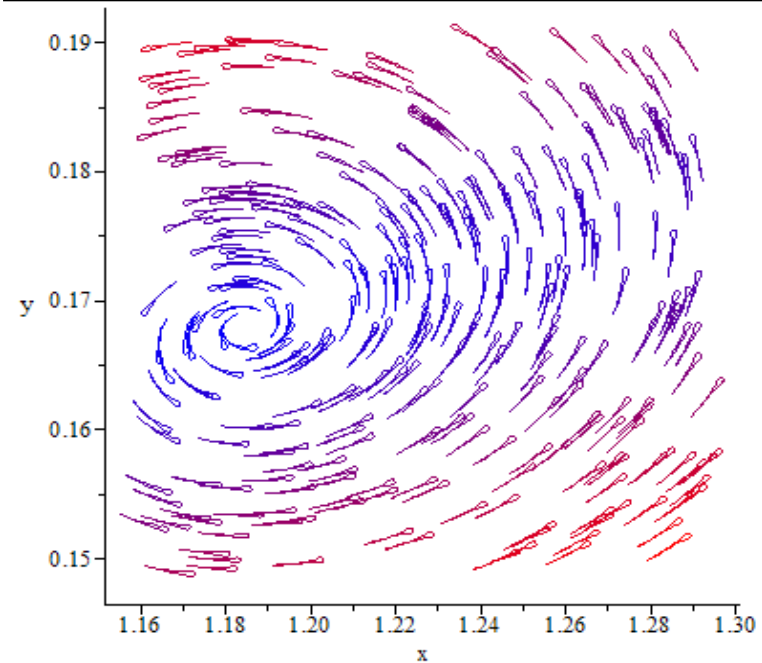

Gambar (3). Bentuk kurva solusi populasi mangsa pemangsa

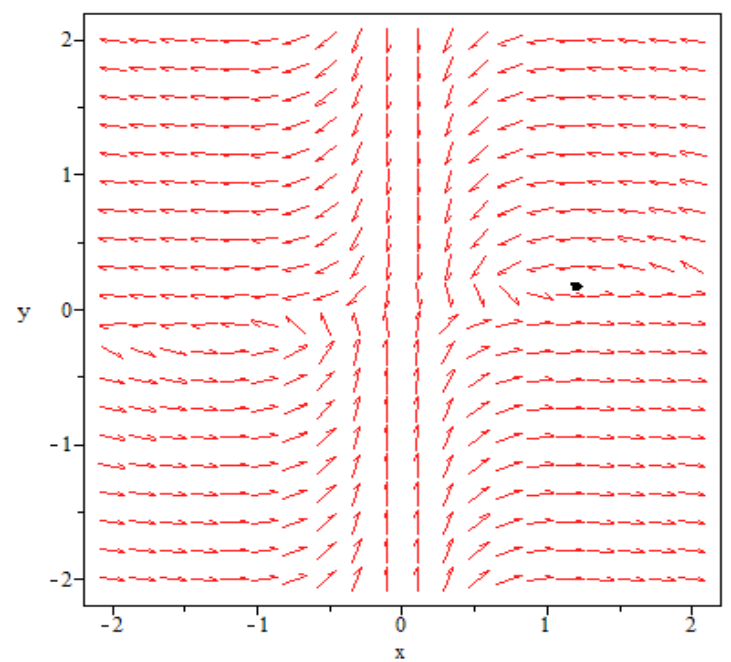

Gambar (4). Bentuk kurva solusi populasi mangsa pemangsa

\section{SIMPULAN DAN SARAN}

Hasil kajian menunjukan bahwa model mangsa pemangsa yang mengikuti tipe Holling III dengan usaha pemanenan pada kedua populasi tersebut diperoleh titik interior $T E_{2}^{*}\left(N_{1}^{*}, N_{2}^{*}\right)$ stabil asimptotik yang berdasarkan kriteria kestabilan Hurwitz test. Selanjutnya, juga diperoleh keuntungan maksimal berdasarkan kegiatan usaha pemanenan pada populasi spesies mangsa pemangsa. Meskipun terjadi dieksploitasi dengan kegiatan usaha pemanenan kedua spesies populasi mangsa pemangsa tersebut akan tetap eksis dan bertahan hidup (tetap lestari). Kegiatan pemanenan yang dilakukan memberikan keuntungan maksimal yaitu sebesar $\pi_{\max }=162.678$ dimungkinkan terjadi dipuncak (titik kritis) dari permukaan suatu fungsi keuntungan. Adapun saran bagi penelitian berikutnya yaitu dengan menambahkan beberapa asumsi-asumsi seperti pengaruh waktu tunda dalam mengamati perubahan dinamika populasi mangsa pemangsa dari waktu ke waktu.

\section{DAFTAR PUSTAKA}

Agarwal, M. (2012). No Title Persistence and Optimal Harvesting of Prey-Predator Model with Holling Type III Functional Response. International Journal of Engineering, Science and Technology, 4(3), 78-96.

Didiharyono, D. (2016). Stability Analysis of One Prey Two Predator Model with Holling Type III Functional Response and Harvesting. Journal of Math Sciences, 1(2), 50-54.

Dubey, B. Agarwal, S. \& Kumar, A. (2018). Optimal Harvesting Policy of a Prey-Predator Model with Crowley-Martin-type Functional Response and Stage Structure In The Predator. Nonlinear Analysis: Modelling and Control, 23(4), 493-514. 
Jiang, Q. \& Wang, J. (2013). Qualitative analysis of a harvested predator-prey system with Holling type III functional response. Advances in Difference Equations, 2013, 1-14. https://doi.org/10.1186/1687-1847-2013-249

Kar, T. K. (2005). Stability analysis of a prey-predator model incorporating a prey refuge. Communications in Nonlinear Science and Numerical Simulation, 10, 681-691.

Liu, X. \& Xing, Y. (2012). Qualitative analysis for a predator prey system with holling type III functional response and prey refuge. Discrete Dynamics in Nature and Society, 2012. https://doi.org/10.1155/2012/678957

Toaha, S. (2013). Pemodelan Matematika dalam Dinamika Populasi. Makassar: Dua Satu Press.

Toaha, S. Hassan, M. A. Ismail, F \& June, L. W. (2008). Stability Analysis and Maximum Profit of One Prey-Two Predators Model under Constant Effort of Harvesting. Malaysian Journal of Science, 26(3), 43-51.

Zhang, X. et al. (2011). Periodic Solution In A Delayed Predator Prey Model with Holling Type III Functional Response and Harvesting Term. World Journal of Modelling and Simulation, 7(1), 70-80.

Zhao, J. Zhao, M \& Yu, H. (2013). Effect of Prey Refuge on the Spatiotemporal Dynamics of a Modified Leslie-Gower Predator-Prey System with Holling Type III Schemes. Entropy, 15(12), 2431-2447. 